\title{
Respiratory System Findings End Day
}

National Cancer Institute

\section{Source}

National Cancer Institute. Respiratory System Findings End Day. NCI Thesaurus. Code C123960.

The final day of the respiratory system assessment. 